\title{
Detección de metapneumovirus humano en niños hospitalizados por infección respiratoria aguda baja en Santiago, Chile
}

\author{
Vivian Luchsinger F, Carola Escobar C, \\ Luis Fidel Avendaño $C$. \\ Detection of human \\ metapneumovirus in children \\ hospitalized for acute \\ lower respiratory infection in \\ Santiago, Chile
}

Background: Human metapneumovirus (hMPV) has recently been described as a new causal agent of acute low respiratory infection (ALRI) in children. In South America, detection has been reported only in Brazil and Argentina. Aim: To detect hMPV in children hospitalized for ALRI in Santiago, Chile. Material and Methods: Reverse transcription-polymerase chain reaction (RT-PCR) was used to detect N gene of hMPV in 182 nasopharyngeal aspirates that were negative for common respiratory viruses, obtained from children hospitalized for ALRI during 2003. Results: Ten samples (5.4\%) were positive, most of them detected during spring months. Conclusions: Since hMPV was detected among infants with ALRI in Santiago, further studies on their prevalence should be done in South America (Rev Méd Chile 2005; 133: 1059-64).

(Key Words: Metapneumovirus, human; Polymerase chain reaction; Respiratory tract infections)

Recibido el 23 de diciembre, 2004. Aceptado el 19 de abril, 2005.

Programa de Virología, Instituto de Ciencias Biomédicas, Facultad de Medicina, Universidad de Chile, Santiago, Chile.

Correspondencia a: Dra. Vivian Luchsinger F. Instituto de Ciencias Biomédicas, Facultad de Medicina, Universidad de Chile. Independencia 1027, Santiago, Chile. Fono: 56-26786317. Fax: 56-2-6786124.

E mail: vluchsin@med.uchile.cl. 
$\mathrm{M}$ etapneumovirus humano (hMPV) es un virus de reciente descripción detectado en niños, adultos y ancianos con enfermedades respiratorias. Las manifestaciones clínicas asociadas a esta infección varían desde síntomas respiratorios leves, hasta infección respiratoria aguda baja (IRAB), como neumonía y bronquiolitis ${ }^{1}$; también se describen infecciones asintomáticas. Al igual que el virus respiratorio sincicial (VRS), se ha clasificado en la familia Paramyxoviridae, subfamilia Pneumovirinae, pero en un género diferente, Metapneumovirus. En el mundo se han identificado dos grupos genéticos, A y B, cada uno de los cuales, a su vez, se subdivide en los subgrupos 1 y $2^{2}$.

Las dificultades en el aislamiento viral debido a la selectividad, lento crecimiento y efecto citopático inespecífico del virus ${ }^{3}$, han estimulado la aplicación de métodos moleculares para la detección viral, como la reacción en cadena de la polimerasa (RCP), técnica rápida y de alta sensibilidad.

Desde su descubrimiento en Holanda ${ }^{1}$, el virus se ha detectado en diversos países, con incidencias variables dependiendo de las condiciones de estudio, tales como edad y sexo de los pacientes, estación climática y métodos diagnósticos aplica$\operatorname{dos}^{4-7}$. En Sudamérica, en forma reciente se ha publicado la detección en Brasil y Argentina, con incidencias de $11 \%^{8}$ y $17 \%^{9}$, respectivamente. El estudio argentino incluyó muestras negativas para virus respiratorios comunes de niños menores de 5 años con infecciones respiratorias bajas entre 1998 y 2002, detectando una incidencia mayor en los meses primaverales, entre septiembre y noviembre $^{9}$. En Brasil, se estudiaron VRS y hMPV en muestras de menores de 3 años con IRAB; hMPV se detectó entre abril y mayo de 2002, período que corresponde al inicio de la estación lluviosa y a la mayor incidencia de $\mathrm{VRS}^{8}$. En Chile, la infección respiratoria es la primera causa de hospitalización durante la infancia y constituye un frecuente motivo de muerte a esta edad, siendo los virus, en especial el VRS, los principales agentes causales ${ }^{10}$. No obstante los avances tecnológicos, aún persiste una alta proporción de casos sin que se logre establecer la etiología. Nuestro objetivo fue detectar hMPV en niños hospitalizados por IRAB durante un año calendario en Santiago.

\section{Materiales y Métodos}

Muestras respiratorias. La vigilancia de virus respiratorios incluyó muestras de aspirado nasofaríngeo (ANF) de 287 lactantes, menores de 2 años, hospitalizados por IRAB en el hospital Roberto del Río, entre enero y diciembre de 200310,11. Se excluyeron niños prematuros, con obstrucciones respiratorias recurrentes, asmáticos y con enfermedades de base neurológica, cardíaca o pulmonar crónicas. Los aspirados nasofaríngeos obtenidos en las primeras $48 \mathrm{~h}$ de hospitalización, se procesaron para aislamiento viral (AV) y detección antigénica por inmunofluorescencia indirecta (IFI) para VRS, adenovirus, virus influenza A y B y parainfluenza 1 a 3 , como se ha descrito ${ }^{10}$. En la IFI se utilizaron anticuerpos monoclonales (VRS A+B: 18B2, Dijon, France; Ad: antiadenovirus de ratón MAB 805, Chemicon Int ${ }^{\circledR}$; parainfluenza 1, 2 y 3: MAB 819, Chemicon Int ${ }^{\circledR}$; Influenza A: MAB 8251, Chemicon Int ${ }^{\circledR}$; Influenza B: MAB 8661, Chemicon Int ${ }^{\circledR}$ ) y conjugado comercial (SIGMA ${ }^{\circledR}$ ). El proyecto contó con la aprobación de la Comisión de Ética de la Facultad de Medicina, Universidad de Chile.

Transcripción Reversa-Reacción en cadena de la polimerasa (TR-RCP) para hMPV. Se analizaron todos los ANF con AV, IFI o ambos negativos para los virus respiratorios antes mencionados. El ARN se extrajo a partir de 0,5 ml del aspirado por el método de isotiocianato de guanidinio-fenol-cloroformo ${ }^{12}$. Se incubaron partidores aleatorios $(5 \mu \mathrm{M})$ (Random hexamer primers, Amersham Bioscien$\left.\mathrm{ce}^{\circledR}\right)$ con $4 \mu \mathrm{l}$ de la muestra en un volumen total de $10 \mu \mathrm{l}$, a $95^{\circ} \mathrm{C}$ por $3 \mathrm{~min}$ y $25^{\circ} \mathrm{C}$ por $25 \mathrm{~min}$ en un termociclador Perkin Elmer Gene Amp ${ }^{\circledR}$ PCR System 2400. La TR-RCP se realizó con partidores específicos para el gen $\mathrm{N}$ del hMPV, un gen altamente conservado en el genoma viral, seleccionados por su mayor sensibilidad para amplificar este virus desde muestras clínicas y aislados virales, según lo descrito por Cotê y cols ${ }^{13}$. Para la síntesis del ADN complementario se incubaron $200 \mathrm{U}$ de transcriptasa reversa de M-MLV (Promega ${ }^{\circledR}$ ), $20 \mathrm{U}$ de inhibidor recombinante de Ribonucleasa (Prome$\left.\mathrm{ga}^{\circledR}\right)$, desoxinucleótidos trifosfatos (dNTP) (1 $\mathrm{mM})$, partidor N1 $(0,5 \mu \mathrm{M})$, solución M-MLV $5 \mathrm{X}$ y 10 ul del producto del paso previo, en un volumen total de $20 \mu \mathrm{l}$, a $37^{\circ} \mathrm{C}$ por $60 \mathrm{~min}$ y $95^{\circ} \mathrm{C}$ por $5 \mathrm{~min}$. 
La RCP se realizó con $\mathrm{MgCl}_{2}(2 \mathrm{mM})$, dNTP $(0,2$ $\mathrm{mM})$, partidores $\mathrm{N}-2$ y N-3 $(0,5 \mu \mathrm{M}), 2,5 \mathrm{U}$ de Taq ADN polimerasa (Promega ${ }^{\circledR}$ ), solución de Taq ADN pol $10 \mathrm{X}$ y $5 \mu \mathrm{l}$ del producto de la TR, completando $100 \mu \mathrm{l}$, en el termociclador a $94^{\circ} \mathrm{C}$ por 10 min, 50 ciclos de $15 \mathrm{~s} \mathrm{a} 94^{\circ} \mathrm{C}, 5 \mathrm{~s}$ a $54^{\circ} \mathrm{C}$ y $30 \mathrm{~s} \mathrm{a}$ $72^{\circ} \mathrm{C}$ y una extensión final a $72^{\circ} \mathrm{C}$ por $10 \mathrm{~min}^{13}$. Los productos amplificados se detectaron por electroforesis en gel de agarosa a 1\%. El tamaño esperado del amplificado fue de $928 \mathrm{bp}$.

En cada reacción, desde la transcripción reversa, se incluyó un control negativo (agua), un control positivo (ARN de cultivo viral en células LLC-MK2) y un ARN plasmidial (GeneAmplimer pAW109 ARN, Applied Biosystems ${ }^{\circledR}$, Inc, Foster City, California). Los cultivos positivos fueron donados gentilmente por Mónica Galiano de Buenos Aires, Argentina ${ }^{9}$ y fueron propagados en pasajes sucesivos en el laboratorio de Virología. El efecto citopático observado fue confirmado por TR-RCP de los genes $\mathrm{N}$ y $\mathrm{F}$ del hMPV. Como control negativo adicional, se realizó TR- RCP de ARN extraído de cultivo celular sin infectar.

Análisis del ADN. Para confirmar la identidad del virus detectado, los productos de la RCP se purificaron (QUIAquik PCR purification kit Qiagen $\left.{ }^{\circledR}\right)$, se determinó la secuencia nucleotídica con el kit Big dye Terminator (Applied Biosystems, USA $^{\circledR}$ ) en un secuenciador ABI Prism 377 ADN $^{\circledR}$, la que se alineó con la secuencia publicada del gen $\mathrm{N}$ de hMPV (número de acceso de GenBank NC 004148) mediante el programa CLUSTAL X, Version 1.81.

Estadística. Se aplicó la prueba de la suma de los rangos de Mann-Whitney para la comparación de las medianas de la edad de los pacientes, considerándose un nivel de significancia de $\mathrm{p}<0,05$.

\section{RESULTADOS}

De los 287 casos, sólo 105 (37\%) fueron positivos para uno de los virus respiratorios analizados: 74 VRS (26\%), 17 adenovirus (6\%), 8 virus influenza (3\%), 9 virus parainfluenza (3\%). Resultaron 4 (1\%) muestras positivas para dos virus respiratorios. Un total de $10(5,4 \%)$ de las 182 muestras negativas fueron positivas para hMPV (Figura 1), las que correspondieron a pacientes hospitalizados entre septiembre y diciembre, esto es, durante

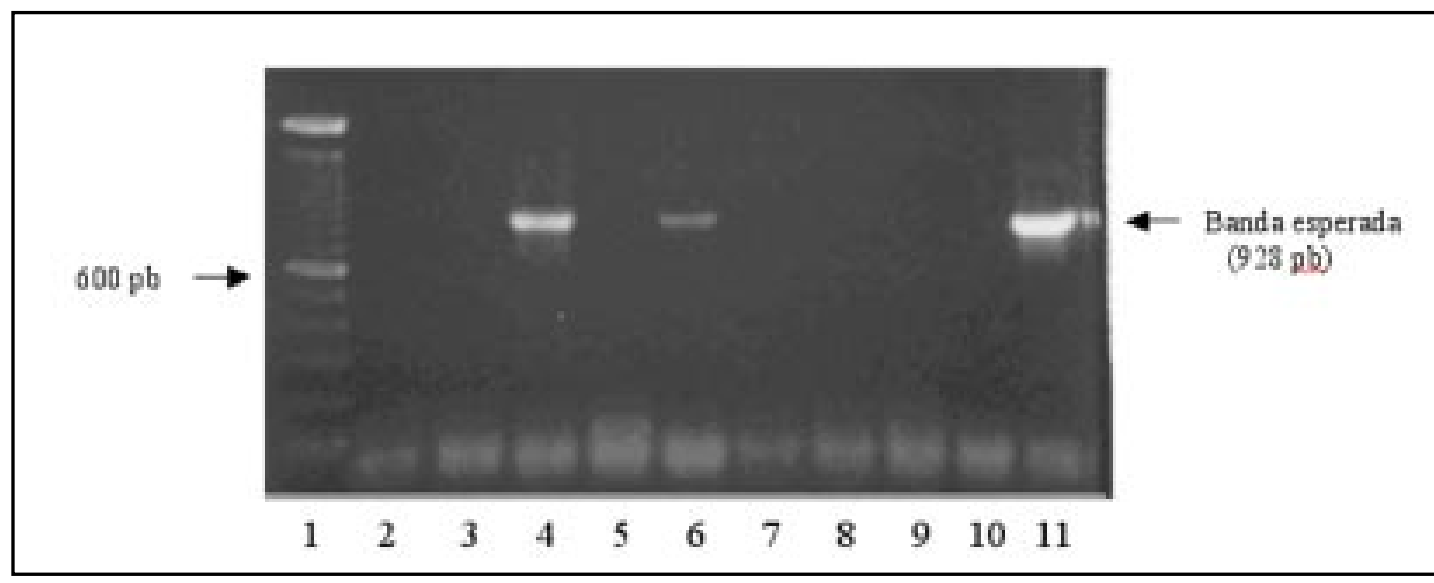

Figura 1. Electroforesis en gel de agarosa $1 \%$ teñido con bromuro de etidio del gen $\mathrm{N}$ de hMPV obtenido mediante TR-RCP. Muestras positivas en carriles 4 y 6 . Muestras negativas en carriles 2, 3, 5, 7 y 8. Control negativo (RNA de LLC-MK2) en carril 9, control negativo (agua) en carril 10 y control positivo en carril 11. En carril 1, marcador de peso molecular ADN de $100 \mathrm{pb}$. 


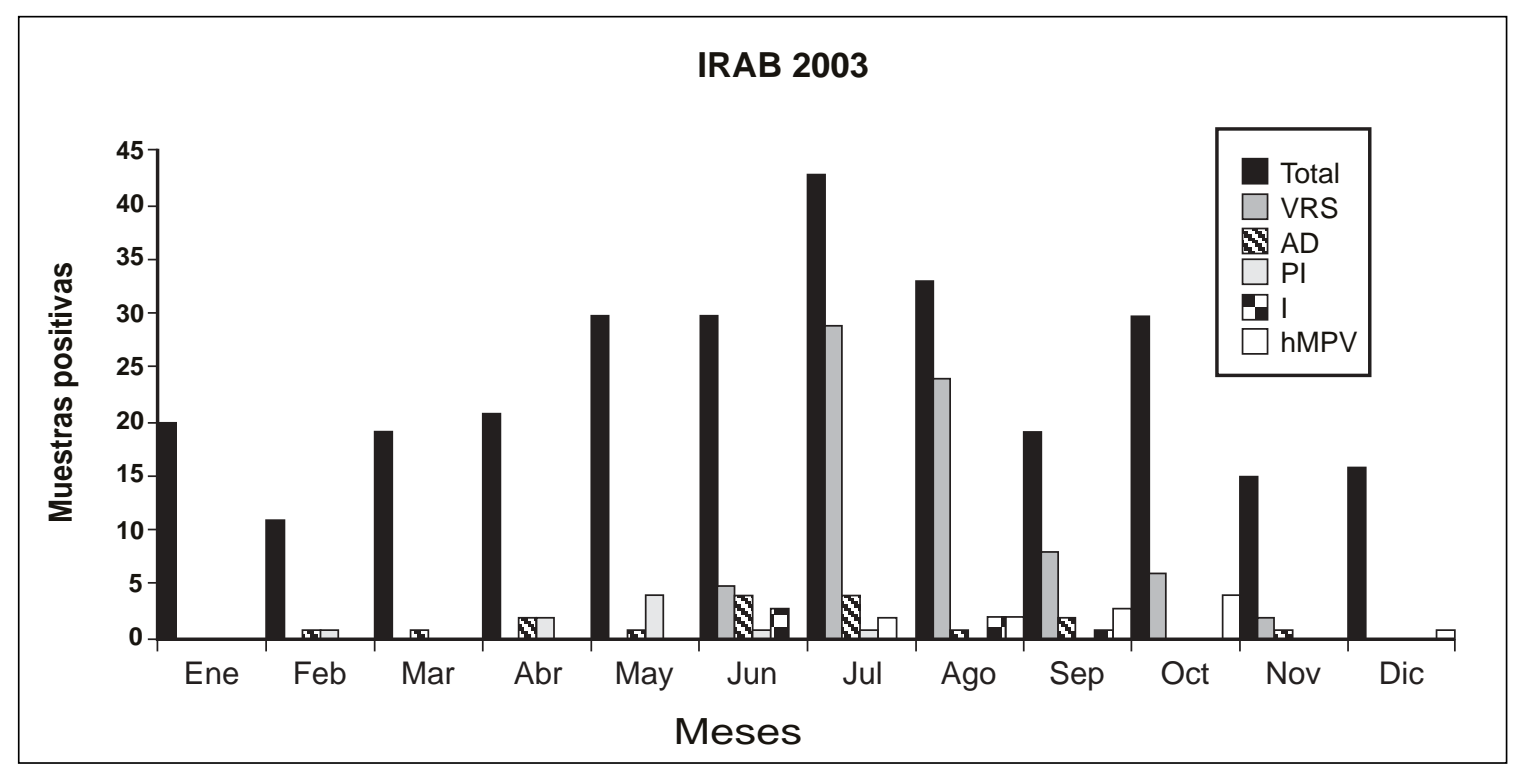

Figura 2. Detección de hMPV y otros virus respiratorios en niños hospitalizados por IRAB en Santiago, enero a diciembre de 2003.

VRS: virus respiratorio sincicial. AD: adenovirus. PI: virus parainfluenza. I: virus influenza. HMPV: metapneumovirus humano

la primavera (Figura 2). El alineamiento de las secuencias nucleotídicas obtenidas mostró 93,4\% de homología entre el amplificado obtenido y la secuencia publicada. La mediana de edad de los casos con hMPV fue de 7 meses (rango 2 a 19 meses), significativamente superior a la de los casos incluidos en la vigilancia (2 meses, rango 11 días a 22 meses) y a la de los niños hospitalizados por VRS ( 3 meses, rango 0 a 22 meses) (suma de los rangos de Mann-Whitney, $p=0,007$ y $p=0,01$, respectivamente). Los diagnósticos de ingreso más frecuentes, tanto en el grupo positivo para hMPV, como en los casos negativos, fueron neumonía y bronquitis obstructiva.

\section{DisCUSIÓN}

El metapneumovirus humano es el agente causal de una proporción significativa de IRAB en niños hospitalizados a nivel mundial. En este estudio, detectamos hMPV en 5,4\% de menores de 2 años hospitalizados por IRAB durante 2003, lactantes en quienes no se detectaron otros virus respirato- rios. Si bien los partidores utilizados en nuestro trabajo corresponden a los previamente descritos como de alta sensibilidad por Cotê y cols ${ }^{13}$, para la amplificación del gen $\mathrm{N}$, muy conservado entre los hMPV, otros autores han postulado que estos partidores serían menos eficientes para detectar los virus del serotipo $\mathrm{B}^{14}$, debido a que se diseñaron en base a las secuencias disponibles del prototipo viral del serotipo A. De esta forma, la frecuencia de $\mathrm{hMPV}$ en niños chilenos podría eventualmente ser mayor. A lo anterior se suma el hecho que sólo analizamos muestras negativas para virus respiratorios comunes, por lo que no se habrían incluido pacientes con infecciones virales mixtas. En este estudio, la detección de VRS y adenovirus fue de $26 \%$ y $6 \%$, respectivamente.

La frecuencia de hMPV detectada concuerda con las cifras publicadas en España y Francia, en niños de $\leq 3$ años con IRAB negativa para otros virus respiratorios ${ }^{15}$, pero es menor a los porcentajes encontrados en Argentina y Brasil $1^{8,9}$. En el estudio brasileño, a diferencia del nuestro en que se incluyeron sólo muestras negativas, se investigó la presencia de hMPV y VRS en forma simultánea. 
La detección del metapneumovirus en lactantes hospitalizados por IRAB en Chile y Argentina fue principalmente durante la primavera ${ }^{9}$. Sin embargo, en otros países la incidencia mayor ha sido durante los meses fríos ${ }^{6,16,17}$. Por esto, es necesario realizar estudios epidemiológicos adicionales, los que se verán facilitados por nuestro sistema de vigilancia de virus respiratorios implementado desde $1989^{11}$ y por la posibilidad de utilizar la TR-RCP en muestras congeladas. De esta forma, esperamos conocer la distribución estacional en los años previos, así como la frecuencia de infecciones respiratorias virales mixtas ${ }^{18}$.

Los lactantes hospitalizados infectados por hMPV eran significativamente de mayor edad que los casos

\section{REFERENCIAS}

1. Van Den Hoogen B, De Jong JC, Groen J, Kuiken T, De Groot R, Fouchier R et al. A newly discovered human pneumovirus isolated from young children with respiratory tract disease. Nat Med 2001; 7: 719-24.

2. Van Den Hoogen B, Herest S, Sprong L, Cane P, Forleo-Neto E, De Swart R et al. Antigenic and genetic variability of Human Metapneumoviruses. Emerg Infect Dis 2004; 10: 658-66.

3. Mackay IM, Jacob KC, Woolhouse D, Waler K, Syrmis MW, Whiley DM ET AL. Molecular assays for detection of human metapneumovirus. J Clin Microbiol 2003; 41: 100-5.

4. Peret TC, Boivin G, Li Y, Couillard M, Humphrey C, Osterhaus A et al. Characterization of human metapneumoviruses isolated from patients in North America. J Infect Dis 2002; 185: 1660-3.

5. Bastien N, Ward D, Van Caeseele P, Brandt K, Lee SHS, McNABB G ET AL. Human metapneumovirus infection in the Canadian population. J Clin Microbiol 2003; 41: 4642-6.

6. Osterhaus A, Fouchier R. Human metapneumovirus in the community. Lancet 2003; 361: 890-1.

7. Stockton J, Stephenson I, Fieming D, Zambon M. Human metapneumovirus as a cause of community-acquired respiratory illness. Emerg Infect Dis 2002; 8: 897-901.

8. Cuevas E, Ben Nasser AM, Dove W, Gurgel RQ, Greensill J, Hart CA. Human metapneumovirus con VRS, con una mediana de 7 meses y 3 meses, respectivamente $(p=0,01)$. Esto concuerda con lo informado por Peiris y cols, en Hong Kong ${ }^{19}$.

El HMPV debe ser incluido en la lista de posibles causas de IRAB y su detección debe ser implementada en forma rutinaria para disminuir los casos con etiología desconocida. Sin embargo, aún no se dispone de un método diagnóstico simple, sensible y rápido como los utilizados para VRS. En conclusión, en este estudio detectamos la presencia de hMPV en niños chilenos hospitalizados por IRAB. Es necesario definir localmente la importancia de hMPV como una nueva causa de IRAB en este grupo de pacientes, así como en ancianos e inmunocomprometidos ${ }^{20}$.

and respiratory syncycial virus, Brazil. Emerg Infect Dis 2003; 9: 1626-8.

9. Galuano M, Videla C, Puch SS, Martínez A, EchavarRía M, Carballal G. Evidence of human metapneumovirus in children in Argentina. J Med Virol 2004; 72: 299-303.

10. Avendaño LF, Palomino MA, Larrañaga C. Surveillance for respiratory syncytial virus in infants hospitalized for acute lower respiratory infection in Chile (1989 to 2000). J Clin Microbiol 2003; 41: 4879-82.

11. Palomino Ma, Larrañaga C, Vimagra E, Camacho J, AvENDAÑO LF. Adenovirus and respiratory syncytial virus-adenovirus mixed acute lower respiratory infections in Chilean infants. Pediatr Infect Dis J 2004; 23: 337-41.

12. Chomczynski P, SAcChI N. Single step method of RNA isolation by acid guanidinium thiocyanatephenol-chloroform extraction. Anal Biochem 1987; 162: 156-9.

13. Cоте $\mathrm{S}, \mathrm{Abed}$ Y, Borvin G. Comparative evaluation of real-time PCR assays for detection of the human metapneumovirus. J Clin Microbiol 2003; 41: 3631-5.

14. Maertzdorf J, Wang C, Brown J, Quinto J, Chu M, De GraAf M et al. Real-Time reverse transcriptase PCR assay for detection of human Metapneumoviruses from all known genetic lineages. J Clin Microbiol 2004; 42: 981-6.

15. Hamelin M, Abed Y, Boivin G. Human metapneumoviruses: a new player among respiratory viru- 
ses. Clin Infect Dis 2004; 38: 983-90.

16. Freymuth F, Vabret A, Legrand L, Eterradossi N, LafayDeiaire F, Brouard J et al. Presence of the new human metapneumovirus in French children with bronchiolitis. Pediatric Infect Dis 2003; 22: 92-4.

17. Nissen MD, Siebert DJ, Mackay IM, SLoots TP, WITHERS SJ. Evidence of human metapneumovirus in Australian children. Med J Aust 2002; 176: 188.

18. Kajon A, Larrañaga C, SuÁrez M, Wadel G, AvendaÑo LF. Genome type analysis of Chilean adenovirus strains isolated in a children's hospital between 1988 and 1990. J Med Virol 1994; 42: 16-21.

19. Peiris J, Tang W, Chan K, Khong P, Guan Y, Lau Y ET AL. Children with respiratory disease associated with metapneumovirus in Hong Kong. Emerg Infect Dis 2003; 9: 628-33.

20. Falsey A, ERdman D, Anderson L, Walsh E. Human Metapneumovirus infections in young and elderly adults. JID 2003; 187: 785-90.

Agradecimientos

Agradecemos a Mónica Galiano por la gentil donación del control positivo de hMPV; a Mónica Peña, Cristián Moreno y Luis Torres por su excelente asistencia técnica. 